\title{
O JULGAMENTO DO HABEAS CORPUS N. 143.641 A PARTIR DE UMA PERSPECTIVA DE DIREITOS REPRODUTIVOS
}

The judgment of Habeas Corpus n. 143.641 from the perspective of reproductive rights

${ }^{1}$ Centro Universitário Ritter dos Reis. Porto Alegre/RS, Brasil.

${ }^{2}$ Pontifícia Universidade Católica do Rio Grande do Sul. Porto Alegre/RS, Brasil.

Correspondência: Marina Nogueira de Almeida.E-mail: almeida.marinan@gmail.com

Recebido: 19/11/2018. Revisão: 28/07/2019. Aprovado: 09/09/2019. 


\section{RESUMO}

Partindo-se da premissa de que os direitos reprodutivos são efetivados a partir do direito à saúde e incluindo-os no âmbito do Direito Sanitário, este comentário de jurisprudência visa a estudar, em uma perspectiva de direitos reprodutivos, o Habeas Corpus n. 143.641, que versa sobre a maternidade e o cárcere. Inicialmente, conceituam-se os direitos reprodutivos com base sua inserção no rol dos direitos humanos. Na segunda parte, busca-se compreender a maternidade e o cárcere a partir da análise de aspectos do Código de Processo Penal e, principalmente, da jurisprudência do Habeas Corpus n. 143.641. Utiliza-se método dedutivo do estudo da doutrina jurídica para o caso. Conclui-se que a pauta dos direitos reprodutivos está presente nas discussões jurídicas brasileiras sobre maternidade e cárcere, mas seu exercício ainda não é pleno.

\section{Palavras-Chave}

Direitos Reprodutivos; Habeas Corpus 143.641; Maternidade no Cárcere.

\section{ABSTRACT}

Starting from the premise that the reproductive rights are effective through the right to health and including them in the sphere of Health Law, this comment on jurisprudence aims to study, from the perspective of reproductive rights, the Habeas Corpus 143.641, that approaches motherhood and imprisonment. Firstly, the reproductive rights are conceptualized with respect to their insertion in human rights. The second part attempts to understand motherhood and imprisonment, through the analysis of aspects of the Criminal Procedural Code and, mainly, from the jurisprudence of Habeas Corpus 143.641. The method used is deductive from the juridical knowledge of the case. The conclusion is that although reproductive rights are present in Brazilian debates about motherhood and imprisonment, these rights are not fully exercised yet.

\section{Keywords}

Reproductive Rights; Habeas Corpus 143.641; Maternity in Prison. 


\section{Introdução}

A discussão sobre reprodução humana foi historicamente atribuída às ciências biológicas e da saúde. Na pauta dos direitos, até pelo menos meados do século $\mathrm{XX}$, os assuntos envolvendo a capacidade reprodutiva das mulheres e seu controle não assumiam uma linguagem própria de direitos. Posteriormente, com o avanço da luta feminista e dos direitos humanos das mulheres, a pauta da saúde reprodutiva foi incluída no rol dos direitos humanos, sob a denominação de direitos reprodutivos - que por vezes aparecem associados aos direitos sexuais.

O exercício pleno dos direitos reprodutivos é uma questão de saúde porque relaciona-se diretamente com o "o estado de completo bem-estar físico, mental e social”, na forma do que definiu a Organização Mundial da Saúde (OMS). Ademais, seu exercício ocorre, ou deixa de ocorrer, no âmbito da saúde pública. A prestação dos serviços afeitos aos direitos reprodutivos deve ocorrer no âmbito do Sistema Único de Saúde (SUS). A maternidade saudável, questão central na discussão dos direitos reprodutivos, é matéria de saúde pública porque impõe ao Estado que atue prestando serviços para atingir esse fim.

O objetivo deste artigo é traçar comentários ao julgamento do Habeas Corpus (HC) n. 143.641/SP, julgado pelo Supremo Tribunal Federal (STF), com relatoria do ministro Ricardo Lewandowski, a partir de uma ótica de direitos reprodutivos. Para isso, busca-se compreender a inclusão dos direitos reprodutivos no rol de direitos humanos e, com a compreensão crítica do que são os direitos reprodutivos, passa-se à jurisprudência que aqui se pretende comentar. O HC n. 143.641 consubstancia a relação entre maternidade e cárcere e pode ser apreciado de muitas formas, inclusive à luz dos direitos reprodutivos - o que aqui se pretende. A metodologia utilizada é dedutiva, na qual é feita a análise dos instrumentos normativos que formulam os direitos reprodutivos a partir do referencial teórico, para, então, analisar o caso específico. Buscam-se traçar considerações acerca do exercício dos direitos reprodutivos pelas mulheres mães atualmente recolhidas no sistema prisional brasileiro.

\section{Os direitos reprodutivos em uma perspectiva crítica}

Os direitos humanos ditos reprodutivos são constituídos "por princípios e normas de direitos humanos que garantem o exercício individual, livre e responsável da sexualidade e reprodução humana"1.

$\mathrm{Na}$ Convenção para a Eliminação de Todas as Formas de Violência contra a Mulher, os direitos reprodutivos aparecem no artigo 16-1 (e), que determina que, nas relações familiares, os Estados-partes devem se obrigar a adotar medidas para que homens e mulheres tenham "os mesmos direitos de decidir livre e responsavelmente

\footnotetext{
${ }^{1}$ VENTURA, Miriam. Direitos reprodutivos no Brasil. Brasília-DF: UNFPA, 2009. p. 19.
} 
sobre o número de seus filhos e sobre o intervalo entre os nascimentos e a ter acesso à informação, à educação e aos meios que lhes permitam exercer esses direitos"2. Dele decorrem o direito ao acesso a métodos contraceptivos e demais meios necessários para o exercício livre da autonomia reprodutiva, o direito à esterilização contraceptiva voluntária e à vedação da esterilização involuntária, à maternidade segura e até mesmo ao polêmico direito de interrupção de gravidez não planejada.

Pode-se traçar crítica feminista à igualdade universalista proposta nos documentos oficiais de direitos humanos, especificamente a esse artigo 16-1 (e). Nota-se que a redação proposta dá os mesmos direitos a homens e mulheres quando trata da decisão de caráter de planejamento familiar. Dessa forma, tal norma pode justificar uma obrigatoriedade do consentimento do companheiro sobre o uso de métodos contraceptivos e, em caso de legalidade, do aborto, enquanto, na realidade, são as mulheres que ficam grávidas e, normalmente, a elas se atribui a responsabilidade pela criação e educação dos filhos ${ }^{3}$. Ademais, a igualdade no direto de decidir deveria refletir em uma distribuição equânime dos riscos e benefícios do uso de métodos contraceptivos, quando o que se tem hoje é uma responsabilidade quase exclusivamente feminina pela contracepção, além de uma série de efeitos colaterais danosos à saúde da mulher em razão do uso de anticoncepcionais. É de importância indiscutível a inserção dos diretos reprodutivos, ainda que na forma do planejamento familiar, na convenção de direitos humanos específica sobre mulheres, reconhecendo a importância do controle da mulher sobre o próprio corpo. Dar tratamento de igualdade formal entre homens e mulheres na fecundidade e na reprodução, contudo, é prejudicial em termos de igualdade material porque desconsidera a condição assimétrica de homens e mulheres no âmbito privado do casal.

No fórum de 1994 da Conferência Internacional sobre População e Desenvolvimento (Plataforma de Cairo), os direitos reprodutivos e a saúde reprodutiva foram oficializados como princípios. O direito ao cuidado da saúde reprodutiva foi expressamente incluído, como o planejamento familiar e a saúde sexual ${ }^{4}$. A IV Conferência Mundial sobre a Mulher, ocorrida em 1995 em Pequim, por sua vez, dedicou-se a mais amplamente conceituar a saúde reprodutiva e os direitos reprodutivos.

${ }^{2}$ BRASIL. Decreto n. 4.377, de 13 de setembro de 2002. Promulga a Convenção sobre a Eliminação de Todas as Formas de Discriminação contra a Mulher, de 1979, e revoga o Decreto n. 89.460, de 20 de março de 1984. Disponível em: http://www.planalto.gov.br/ccivil_03/decreto/2002/D4377.htm. Acesso em: 25 set. 2019.

${ }^{3}$ CORREA, Sonia; PETCHESKY, Rosalind. Direitos sexuais e reprodutivos: uma perspectiva feminista. Physis [online]. 1996, v. 6, n. 1-2, p. 147-177. http://dx.doi.org/10.1590/S0103-73311996000100008. Disponivel em: http://www.scielo.br/pdf/physis/v6n1-2/08.pdf.

${ }^{4}$ UNITED NATIONS POPULATION FUND (UNFPA). Report of the International Conference on Population and Development. Cairo, 5-13 Sept. 1994. New York: United Nations, 1995. Disponível em: https://www.un.org/en/ development/desa/population/events/pdf/expert/27/SupportingDocuments/A_CONF.171_13_Rev.1.pdf.

${ }^{5}$ UNITED NATIONS. Fourth World Conference on Women. Beijing Declaration and Plataform for Action. Pequim, 1995. Disponível em: https://www.un.org/en/events/pastevents/pdfs/Beijing_Declaration_and_ Platform_for_Action.pdf. 
Em termos de positivação como direitos humanos, os direitos reprodutivos são decorrentes do reconhecimento do direito básico individual de controle e autonomia de sua reprodução. Para os fins deste artigo, a principal questão de direitos reprodutivos é o direito a uma maternidade saudável. A maternidade segura aparece expressamente como aspecto da saúde reprodutiva. Logo, é indiscutível que seu exercício seja um direito de toda mulher e que se insere no âmbito tanto dos direitos reprodutivos quanto do direito à saúde.

É preciso cuidado para não se adotar a visão dos direitos reprodutivos como direitos meramente individuais. Ventura ${ }^{6}$ destaca a importância de ver os direitos reprodutivos como envolvendo os direitos individuais de autonomia e liberdade relacionados aos direitos sociais da saúde e da educação. Isso porque os direitos reprodutivos, se vistos enquanto uma liberdade privada de escolha, são apenas um meio de manter as desigualdades de raça, classe, idade e outros marcadores sociais da diferença. Para que sejam efetivos, os direitos reprodutivos devem ser vistos em termos de poder - o poder de tomar decisões - e de recursos - a possibilidade de realizar as decisões de forma saudável e segura ${ }^{7}$. Os direitos reprodutivos, se vistos como direitos sociais, não envolvem somente a liberdade do indivíduo, mas também as obrigações sociais, a ação pública necessária para garantia dos direitos a serem exercidos ${ }^{8}$. Petchesky pontua que é inútil as mulheres terem formalmente os direitos reprodutivos se não puderem exercê-los ${ }^{9}$. Nesse sentido, em relação às mulheres apenadas em condição de mães, o Estado deve fornecer condições para garantia do exercício dos direitos reprodutivos, incluindo-se aqui a maternidade segura, o que acabou por ser um dos objetos do julgado analisado. Antes de adentrar no conteúdo da decisão, é importante realizar, ainda que de forma breve, uma contextualização do encarceramento feminino e das condições em que a maternidade é exercida pelas mulheres privadas de liberdade no Brasil, o que se fará no tópico a seguir.

\section{Encarceramento feminino e maternidade: a realidade brasileira}

A vida institucionalizada, levada por aqueles e aquelas que cumprem pena em estabelecimentos prisionais, acaba por refletir muito da realidade - em especial as desigualdades - apresentada na sociedade da qual se origina. Frente a essa premissa, oriunda dos estudos criminológicos ${ }^{10}$, depara-se com o caráter seletivo do Direito Penal, que tende a reproduzir a discriminação projetada pela sociedade sobre

\footnotetext{
${ }^{6}$ UNITED NATIONS POPULATION FUND (UNFPA). Report of the International Conference on Population and Development, cit.

${ }^{7}$ CORREA, Sonia; PETCHESKY, Rosalind. op. cit.

${ }^{8}$ ld. Ibid.

${ }^{9}$ PETCHESKY, R. Spiraling discourses of reproductive and sexual rights: A Post-Beijing assessment of international feminist politics. In: COHEN, C; JONES, K; TRONTO, 5. Women transforming politics: An alternative reader. Nova York : NYU Press, 1997, pp. 569-587.

${ }^{10}$ CAMPOS, Carmem Hein de (Org.). Criminologia e feminismo. Porto Alegre-RS: Sulina, 1999. p. 14.
} 
pessoas que dispõem de marcadores sociais da diferença, selecionando "as pessoas, quer para criminalizá-las quer para vitimizá-las, recrutando sua clientela entre os mais miseráveis"11.

Dessa forma, analisando-se a população carcerária do Brasil, facilmente percebe-se uma maior presença de homens, negros e pobres. Já no que diz respeito ao encarceramento feminino, mesmo que constituído de contingente consideravelmente menor que o masculino - por exemplo, a população carcerária feminina no Rio Grande do Sul representa 5,1\% do total de indivíduos cumprindo pena nos estabelecimentos prisionais do estado, ou seja, um total de 2.161 detentas $^{12}$-, reveste-se de peculiaridades impostas por diversos fatores, dos quais imperioso se faz salientar dois dos mais evidentes: as diferenças biológicas entre os sexos e a característica patriarcal de nossa sociedade ${ }^{13}$.

Por consequência desses dois fatores evidenciados, insurgem as peculiaridades do aprisionamento feminino e, em especial, a problemática da maternidade durante o cumprimento de pena restritiva de liberdade. Assim, para que se possa ter uma melhor compreensão a respeito das consequências e da forma com que essa maternidade ocorre, este artigo se valerá de perspectivas criminológicas associadas às teorias oriundas do movimento feminista.

Nesse contexto, importante salientar que tanto o feminismo como a criminologia não permitem um conceito fechado ou uma análise da evolução histórica do encarceramento feminino em que se observe a exclusão de uma teoria por meio de sua superação por outra mais atual ${ }^{14}$. Ao contrário disso, observam-se diversas teorias aplicáveis ao momento histórico em que se vive, das quais faremos uso na tentativa de compreender as especificidades do encarceramento feminino.

As teorias feministas, conforme classificação adotada por Alimena ${ }^{15}$, podem ser divididas em três ondas. A primeira, fundada no feminismo liberal, tem como principal característica a luta por igualdade entre os sexos, buscando ampliar os direitos à educação e ao trabalho; a segunda, calcada no chamado feminismo radical, assinala-se pela diferença, procurando dirimir a disparidade de poder entre os sexos através de mecanismos, principalmente estatais, de defesa à mulher; e a terceira onda,

\footnotetext{
${ }^{11}$ ESPINOZA, Olga. A prisão feminina desde um olhar da criminologia feminista. Revista Transdisciplinar de Ciências Penitenciárias, Pelotas, v.1, n. 1, p. 35, jan./dez. 2002. Disponível em: https://antares.ucpel.tche. br/ojs/index.php/PENIT/article/viewFile/34/33. Acesso em: 18 jul. 2012.

${ }^{12}$ Dados obtidos através de relatório gerado pelo Departamento de Planejamento da SUSEPE, atualizado em 10/07/2019. SUPERINTENDÊNCIA DOS SERVIÇOS PENITENCIÁRIOS - SUSEPE. Departamento de Planejamento. Relatório atualizado em 10/07/2019. Disponível em: http://www.susepe.rs.gov.br/capa. php. Acesso em 19 jul. 2019.

${ }^{13}$ ESPINOZA, Olga. A mulher encarcerada em face do poder punitivo. São Paulo: IBCCRIM, 2004. p. $122-123$.

${ }^{14}$ CARVALHO, Salo de. Criminologia cultural, complexidade e as fronteiras de pesquisa nas ciências criminais. Revista Brasileira de Ciências Criminais, São Paulo, v. 17, n. 81, p. 294-338, nov./dez. 2009.

${ }^{15}$ Optamos por utilizar a classificação adotada por Carla Alimena, no entanto, a respeito também nos valemos dos ensinamentos de Carmen Hein Campos in: CAMPOS, Carmem Hein de (Org.). op. cit.
} 
assentada no feminismo socialista, considera a pluralidade das "diversas mulheres" presentes na sociedade, apontando a multiplicidade de fatores que acabam por provocar desigualdades entre os gêneros, tais como classes sociais, etnias, idade etc ${ }^{16}$.

A última onda feminista aproxima-se da chamada teoria queer ${ }^{17}$, a qual aduz que a diferenciação dos sexos é cultural: é a cultura que os trata de forma peculiar, fixando os papéis sociais de cada gênero ${ }^{18}$. Dessa forma, é possível estabelecer um ponto de encontro entre as teorias feministas e a criminologia crítica e cultural, uma vez que as diferenças de gênero se dão, principalmente, pelas criações culturais de cada sociedade e que, para as mencionadas vertentes criminológicas, tais aspectos culturais relacionam-se com a violência, com o desvio e com o controle da sociedade, fundindo as abordagens feministas aos principais objetos de estudo da criminologia ${ }^{19}$.

A criminalidade feminina vem sendo pauta de estudos criminológicos desde o determinismo lombrosiano, que defendia que as mulheres delinquiam em menor escala do que os homens por fatores unicamente biológicos. Lombroso acreditava que as mulheres teriam evoluído menos que os homens, não estando aptas a realizar os desafios que o crime lhes exigiria ${ }^{20}$. Já Freud acreditava que a criminalidade feminina consistia em um complexo de masculinidade, uma vez que as atitudes agressivas e as condutas desviantes eram características da psique masculina ${ }^{21}$.

Além do estigma normalmente atribuído àquele que delinque, a mulher desviante, em face dessa cultura patriarcal, carrega o rótulo de "criminosa", bem como o de inconsequente e irresponsável (por agir sem pensar na criação dos filhos) $)^{22}$. Também acaba perdendo, perante os demais, sua feminilidade, por praticar condutas socialmente atribuídas ao gênero masculino. Acaba que, mesmo delinquindo em menor expressão, a mulher tem sua punição majorada pelos preconceitos da sociedade ${ }^{23}$.

${ }^{16}$ MARRONE ALIMENA, Carla. A tentativa do (im)possivel: feminismos e criminologias. Rio de Janeiro: Lumen Juris, 2010, p.19-21.

17 “A palavra queer pode significar estranho, excêntrico, fora do lugar, ridículo. Pode também ser uma expressão pejorativa para designar sexualidades não heterossexuais. Os estudos queer re-significam a expressão pejorativa, questionando ordens de sexo, gênero e sexualidade." MARRONE ALIMENA, Carla. op. cit.

${ }^{18}$ RODRIGUES, Carla. Butler e a desconstrução do gênero [Resenha]. Rev. Estud. Fem., Florianópolis, v. 13, n. 1, p. 180, jan./abr. 2005. http://dx.doi.org/10.1590/S0104-026X2005000100012. Disponível em: http://www.scielo.br/pdf/ref/v13n1/a12v13n1.pdf. Acesso em: 11 jul. 2019.

${ }^{19}$ MARRONE ALIMENA, Carla. op. cit.

${ }^{20}$ FERRERO, Guglielmo; LOMBROSO, Cesare. La donna delinquente, la prostituta e la donna normale. Firenze: Torino, 1903. p. 31-47.

${ }^{21}$ LEMGRUBER, Julita. Cemitério dos vivos: análise sociológica de uma prisão de mulheres. Rio de Janeiro: Forense, 1999. p. 2.

${ }^{22}$ LARRAURI, Elena. A mujer ante el derecho penal. Revista de la Asociación de Ciencias Penales de Costa Rica, año 9, n. 11, p. 13-45, jul. 1996. Disponível em: http://www.cienciaspenales.org/REVISTA\%2011/ larrau11.htm. Acesso em: 09 set. 2018.

${ }^{23}$ GARCÍA, Carmen Antony. Mujeres invisibles: las cárceres femeninas en América Latina. Nueva Sociedad, n. 208, p. 73-85, mar./abr. 2007. Disponível em: https://nuso.org/articulo/las-carceles-femeninas-enamerica-latina/. Acesso em: 11 jul. 2019. 
Ao adentrar no aparelho prisional, a mulher passa, por exemplo, a carecer de atenção médica especializada, levando-se em consideração que a maior parte das casas penitenciárias da América Latina não contam com atendimento ginecológico ou obstétrico. Não obstante tal falta de cuidado, diversos estabelecimentos prisionais não possuem recursos humanos suficientes, tendo que, muitas vezes, valer-se de contingente masculino para exercer as funções operacionais da casa deficiência que proporciona uma maior vulnerabilidade das detentas à ocorrência de abusos sexuais ${ }^{24}$.

Em relação às atividades laborais ofertadas, o que se vislumbra massivamente são serviços de tapeçaria, lavagem de roupas e artesanato, reforçando o papel submisso da mulher na sociedade e, ao contrário do que se espera, não dando a essas mulheres condições de se manterem, durante a vida extramuros, de forma independente com os trabalhos ensinados no cárcere ${ }^{25}$. Esse modelo acaba infantilizando as mulheres, impondo-as a uma condição de dependência e incapacidade de tomar decisões.

Em relação a essa institucionalização, importante salientar o pensamento de Goffman a respeito das consequências causadas pelo confinamento em instituições totais, tais quais as prisões:

Se ocorre mudança cultural, talvez se refira ao afastamento de algumas oportunidades de comportamento e ao fracasso para acompanhar mudanças sociais recentes no mundo externo. Por isso, se a estada do internado é muito longa, pode ocorrer, caso ele [o preso] volte para o mundo, o que já foi denominado desculturamento ou destreinamento - que o torna temporariamente incapaz de enfrentar alguns aspectos de sua vida diária ${ }^{26}$.

A situação agrava-se em relação à questão da maternidade durante o cumprimento da pena, circunstância que apresenta uma série de fragilidades ignoradas pelo ordenamento penal. Dentre elas, podemos ressaltar que, quando essas mães entram nas penitenciárias tendo filhos de menor idade, acabam afastadas destes, muitas vezes pelo preconceito de suas famílias, que hesitam em levá-los para visitação, e não raras vezes por falta de condições dos estabelecimentos prisionais para recebê-los ${ }^{27}$.

Notadamente nesses casos, a pena restritiva de liberdade acaba estendendo seus efeitos à família das condenadas, em especial aos filhos. Na composição atual das famílias que integram nossa sociedade, o papel da mulher vai além do papel de

\footnotetext{
${ }^{24}$ GARCÍA, Carmen Antony. op. cit.

${ }^{25}$ LEMGRUBER, Julita. op. cit

${ }^{26}$ GOFFMAN, Erving. Manicômios, prisões e conventos. São Paulo: Perspectiva, 1974. p. 23.

${ }^{27}$ OLIVEIRA, Odete Maria de. A mulher e o fenômeno da criminalidade. In ANDRADE, Vera Regina Pereira de (Org.). Verso e reverso do controle penal (des) aprisionando a sociedade da cultura punitiva. FlorianópolisSC: Fundação Boiuteux, 2003. v. 1, p. 165.
} 
mãe. Nessa nova organização familiar, a mulher, além de cuidar dos filhos, provê o sustento e administra a família. Quando o Estado a retira desse núcleo, causa um problema estrutural, deixando essas crianças sem recursos e sem cuidados, onerando, muitas vezes, pessoas alheias à relação familiar.

O isolamento gerado pela falta de procura por parte da família é somado ao fato de a mulher ainda sofrer restrições em relação à visita íntima. É comum que as penitenciárias femininas, ao contrário das masculinas, não disponham de local apropriado para a realização dessa visita. Além da falta de estrutura, boa parte dos regulamentos internos das prisões impõe uma série de restrições à entrada de parceiros das apenadas, fazendo-os passar por procedimentos que não são observados em estabelecimentos prisionais masculinos. Em certas instituições, a presa só pode receber visita íntima se for casada, o que se aplica à minoria da população carcerária ${ }^{28}$. Assim, as apenadas padecem de um conforto que o contato com seus entes queridos poderia lhes proporcionar.

Por estarem afastadas dos filhos, as detentas acabam submetendo-se a diversas privações ocasionadas pela arbitrariedade da administração e do corpo funcional das penitenciárias, cedendo a tais abusos a fim de não terem obstaculizado seu direito de receber visitas e informações a respeito dos filhos. Por outro lado, além de se afastarem das mães, tais crianças acabam não tendo para onde ir, muitas vezes sendo direcionadas a abrigos ou casas de parentes distantes e, em outras, até mesmo tornando-se moradores de rua $^{29}$.

Quando a gestação se dá no ambiente prisional, a situação agrava-se ainda mais. As enfermarias responsáveis pelos atendimentos médicos das penitenciárias não suportam os cuidados especiais que uma gestante necessita, restringindo o atendimento pré-natal a meras consultas ambulatoriais. Não é difícil encontrar uma gestante que, no quinto mês de gravidez, ainda não realizou nenhuma ecografia, procedimento que, quando a gestante encontra-se em liberdade, normalmente se dá nas primeiras semanas subsequentes à descoberta do estado de gravidez.

Após o nascimento, a Constituição Federal de $1988^{30}$ (CF/88) prevê, em seu artigo $5^{\circ}$, inciso $\mathrm{L}$, que as apenadas poderão permanecer com seus filhos durante $\mathrm{o}$ período de amamentação, bem como o Estatuto da Criança e do Adolescente ${ }^{31}$, em seu artigo $9^{\circ}$, dispõe que o poder público deverá propiciar condições adequadas ao aleitamento materno, inclusive aos filhos de mães submetidas à medida privativa de

\footnotetext{
${ }^{28}$ ESPINOZA, Olga. A prisão feminina desde um olhar da criminologia feminista, cit., p. 53.

${ }^{29}$ SOARES, Barbára; SILVA, lara Ilgenfritz. Prisioneiras: vida e violência atrás das grades. Rio de Janeiro: Garamond, 2002. p. 27.

${ }^{30}$ BRASIL. Constituição da República Federativa do Brasil de 1988. Disponível em: http://www.planalto.gov. br/ccivil_03/constituicao/constituicaocompilado.htm. Acesso em: 25 set. 2019.

${ }^{31}$ BRASIL. Lei n. 8.069, de 13 de julho de 1990. Dispõe sobre o Estatuto da Criança e do Adolescente e dá outras providências. Disponível em: http://www.planalto.gov.br/ccivil_03/leis/18069.htm. Acesso em: 25 set. 2019.
} 
liberdade. Já a Lei de Execução Penal ${ }^{32}$, em seu artigo 89, faz menção a um período que compreende a idade de seis meses a sete anos, no qual os filhos das apenadas poderiam manter-se em berçários ou creches dentro dos estabelecimentos prisionais. No entanto, a legislação não determina um período exato de permanência dos filhos junto das mães.

Com a finalidade de regulamentar tal situação, a Resolução n. 3 do Conselho Nacional de Política Criminal e Penitenciária ${ }^{33}$ define que os filhos de apenadas devem permanecer junto às mães pelo período mínimo de um ano e seis meses. Passado esse período, deve-se iniciar o procedimento gradual de separação e adaptação da criança à família que o acolherá durante o cumprimento de pena da mãe, processo que deverá levar mais seis meses. Dessa forma, as crianças deverão permanecer com as mães até os dois anos de idade, tendo a possibilidade de permanecerem até os sete anos, desde que o estabelecimento prisional cumpra as exigências estruturais previstas no artigo $6^{\circ}$ da referida resolução.

Art. $6^{\circ}$ Deve ser garantida a possibilidade de crianças com mais de dois e até sete anos de idade permanecer junto às mães na unidade prisional desde que seja em unidades materno-infantis, equipadas com dormitório para as mães e crianças, brinquedoteca, área de lazer, abertura para área descoberta e participação em creche externa.

Tendo em vista que, nessa primeira fase da vida, essas crianças compartilham o cárcere com as mães, vislumbra-se mais uma debilidade do aprisionamento feminino. Nessa faceta, além do sofrimento da apenada em gerar um filho em um ambiente violento e deveras inadequado, ocorre a extensão de sua pena para a pessoa do filho. O "encarceramento" dessas crianças "justifica-se" pela manutenção do vínculo materno, bem como pela efetivação do aleitamento, tão necessário ao sadio desenvolvimento de uma criança. No entanto, os submete ao ambiente prisional, sem o convívio com os demais parentes, em locais de estrutura precária, geralmente inapropriados para alojarem até mesmo adultos, quanto mais crianças. As mães e seus bebês carecem de atendimento especializado, alimentação adequada e amparo familiar, o que vai contra toda e qualquer percepção de humanidade, ferindo drasticamente a dignidade da pessoa humana, fundamento do Estado Democrático de Direito que é a diretriz maior para a aplicação e efetividade das normas ${ }^{34}$.

\footnotetext{
${ }^{32}$ BRASIL. Lei n. 7.210, de 11 de julho de 1984. Institui a Lei de Execução Penal. Disponível em: http://www. planalto.gov.br/ccivil_03/leis/I7210.htm. Acesso em: 25 set. 2019.

${ }^{33}$ CONSELHO NACIONAL DE POLÍTICA CRIMINAL E PENITENCIÁRIA. Resolução n. 3, de 11 de março de 2009. Dispõe sobre as Diretrizes Nacionais para a Oferta de Educação nos estabelecimentos penais. Disponível em: http://depen.gov.br/DEPEN/depen/cnpcp/resolucoes/2009/resolucaono3de11demarcode2009. pdf. Acesso em: 25 set. 2019.

${ }^{34}$ SARLET, Ingo Wolfgang. A eficácia dos direitos fundamentais. 9. ed., rev., atual. e ampl. Porto Alegre: Livr. do Advogado, 2008. p. 63-68.
} 
Logo, os castigos corporais, que tanto nos orgulhamos de termos extinguido de nossos sistemas de controle, se fazem presentes. A pena de prisão, com a privação de ar, sol, luz, espaço; o odor, a cor da prisão; as refeições sempre frias; a falta de atendimento médico; a proliferação de doenças; todos esses são fatores que degradam o corpo ${ }^{35}$. Assim, mães e crianças são sujeitas a uma modalidade de tortura física que, mascarada por um processo em que o acusado, devidamente julgado, merece a pena que recebeu, torna essa degradação corpórea aceitável. Os esforços para infligir apenas uma pena justa criam esses sistemas rígidos, insensíveis às necessidades individuais ${ }^{36}$, permitindo que situações como essas se concretizem sem causar estranheza.

Além de todas as limitações já expostas, a imposição do desenvolvimento de crianças a um local restrito e sem o devido acompanhamento familiar é tão prejudicial porque, como nos ensina a Psicologia, é nos primeiros anos de vida que se vislumbram as principais fases de desenvolvimento dos indivíduos; é nesse período que, por fatores hereditários e ambientais, é alicerçado o aparelho psíquico do ser humano, bem como são atribuídas suas principais habilidades motoras e sua capacidade sensorial ${ }^{37}$. Dessa forma, só estará amplamente resguardada a dignidade prevista no artigo 227 da CF/88 quando o desenvolvimento físico, cognitivo e psicossocial desses infantes estiver preservado, sem sua submissão a um ambiente repreensor e isolado como o dos estabelecimentos prisionais.

Essas mães que acabaram delinquindo, no mais das vezes, por serem oriundas de estratos mais baixos da população e terem suas chances de desenvolvimento econômico-social reduzidas, além de sofrerem este primeiro "descaso" estatal, acabam sofrendo novamente uma intervenção impensada, que desmorona suas famílias e traz seus filhos ao encontro de um sistema opressor e segregatício. Dessa maneira, ao impor a pena restritiva de liberdade, o Estado "cria" um novo problema: a institucionalização das crianças, bem como a falta de suporte para que estas se mantenham longe das mães.

Considerando-se a decadência do sistema penitenciário brasileiro, o que se observa é uma total falta de estrutura dos estabelecimentos prisionais para abrigar indivíduos em estado de peculiar desenvolvimento, tais quais crianças que vivem a chamada primeira infância. Dessa forma, assim como as gestantes, esses infantes carecem de atendimento médico especializado, bem como permanecem aprisionados como se condenados fossem. Essa condenação extensiva infringe um dos mais importantes princípios penais constitucionais: o princípio da personalidade da pena,

\footnotetext{
${ }^{35}$ HULSMAN, Louk; CELIS, Jacqueline Bernat de. Penas perdidas: o sistema penal em questão. Rio de Janeiro: Luam, 1993. p.62.

${ }^{36}$ CHRISTIE, Nils. Los Límites del dolor. México: Fondo de Cultura Económica, 1984. p. 7.

${ }^{37}$ TRINDADE, Jorge. Manual de psicologia jurídica para operadores do direito. Porto Alegre: Liv. do Advogado, 2004. p.59-75.
} 
ou seja, "no direito penal, responsabilidade coletiva, subsidiária, solidária ou sucessiva. Nada pode, hoje, evocar a infâmia do réu que se transmitia a seus sucessores." ${ }^{38}$.

Uma vez que crianças - sujeitos com aparelho psíquico em formação ${ }^{39}$ - são submetidas a um sistema opressivo, de medidas aplicadas em ultima ratio, como se trata o Direito Penal, vislumbra-se a aplicação de uma política criminal confrontante à principiologia que é cerne de nosso ordenamento jurídico. Afastar o infante da presença materna, sem dúvida, acarreta-lhe danos; no entanto, fazer-lhe cumprir uma pena que não merece, em um estabelecimento de condições precárias (como são os estabelecimentos prisionais brasileiros), parece tão danoso quanto.

Portanto, o que se pode concluir é que os ambientes prisionais não estão preparados para receber crianças e que, mesmo que contassem com boa estrutura para abrigá-las, ainda assim não seriam a resposta mais adequada para a solução da maternidade no cárcere. Diante de uma condenação dirigida a uma mãe, imprescindível se faz que o sistema penal conheça seus diversos efeitos e que o julgador conheça a realidade de quem está julgando e a realidade dos locais aos quais a condenação exporá as apenadas, bem como seus filhos ${ }^{40}$.

\section{Os direitos reprodutivos, a maternidade no cárcere e o Habeas Corpus n. 143.641}

Feita a necessária contextualização sobre o encarceramento feminino, volta-se ao debate específico a respeito dos direitos reprodutivos em relação ao HC analisado. No Brasil, os direitos reprodutivos aparecem no texto constitucional de forma mais ou menos explícita. No tocante às mulheres encarceradas, como dito, há a garantia constitucional expressa de que possam permanecer com seus filhos durante $\mathrm{o}$ período de amamentação, na forma do artigo $5^{\circ}$, inciso $\mathrm{L}, \mathrm{da} \mathrm{CF} / 88$. O direito à saúde, expresso no artigo 196 da CF/88, reflete-se diretamente na prestação de cuidados de saúde reprodutiva. O direito brasileiro incluiu na Carta Constitucional diversos pontos sobre a proteção da maternidade nos direitos sociais, na previdência social e na assistência social (por exemplo, art. $6^{\circ}$; art. $7^{\circ}$, XVIII; art. 201, II; e art. 203, I). Os direitos reprodutivos também se apresentam nas normas infraconstitucionais, como a Lei n. $11.108 / 2005^{41}$ e a Lei n. $11.634 / 2007^{42}$.

\footnotetext{
${ }^{38}$ BATISTA, Nilo. Introdução crítica ao direito penal brasileiro. 11. ed. Rio de Janeiro: Revan, 2007. p. 104.

${ }^{39}$ ZIMERMAN, David; COLTRO, Antônio Carlos Mathias. (Orgs.). Aspectos psicológicos da atividade jurídica. Campinas: Millennium, 2002. p. 87-101.

${ }^{40}$ HULSMAN, Louk; CELIS, Jacqueline Bernat de. op. cit.

${ }^{41}$ BRASIL. Lei n. 11.108, de 7 de abril de 2005. Altera a Lei n. 8.080, de 19 de setembro de 1990, para garantir às parturientes o direito à presença de acompanhante durante o trabalho de parto, parto e pósparto imediato, no âmbito do Sistema Único de Saúde - SUS. Disponível em: http://www.planalto.gov.br/ ccivil_03/_Ato2004-2006/2005/Lei/L11108.htm. Acesso em: 25 set. 2019.

${ }^{42}$ BRASIL. Lei n. 11.634, de 27 de dezembro de 2007. Dispõe sobre o direito da gestante ao conhecimento e a vinculação à maternidade onde receberá assistência no âmbito do Sistema Único de Saúde. Disponível em: http://www.planalto.gov.br/ccivil_03/_Ato2007-2010/2007/Lei/L11634.htm. Acesso em: 25 set. 2019.
} 
Por serem direitos humanos, resta necessário que o direito à saúde materna e a viver livre da morte materna evitável atinja todas as mulheres. Assim, a Lei n. 13.257/2016 ${ }^{43}$, o Estatuto da Primeira Infância, alterou o artigo 318 do Código de Processo Penal ${ }^{44}(\mathrm{CPP})$ para permitir a substituição da prisão preventiva pela prisão domiciliar para gestantes (inciso IV) e para mulheres com filhos de até 12 (doze) anos de idade incompletos. Em análise da aplicação dessa conversão de regime pelo Tribunal de Justiça de São Paulo (TJSP), Braga e Franklin ${ }^{45}$ observaram que os julgadores tendiam a colocar a pretensão punitiva como prioridade, negando a prisão domiciliar e, consequentemente, violando a proposta legislativa de proteção da maternidade. Os desembargadores frequentemente faziam um juízo de valor patriarcal e discriminatório, com a impossibilidade de uma "criminosa" ser uma "boa mãe", para fins de negar o direito pleiteado; ou, vendo a maternidade como uma forma de despertar princípios morais mais nobres na apenada, quando do deferimento da medida ${ }^{46}$.

Com a mais recente reforma do CPP, foi impetrado habeas corpus coletivo pela Defensoria Pública da União, tendo por pacientes: “Todas as mulheres submetidas à prisão cautelar no sistema penitenciário nacional, que ostentem a condição de gestantes, de puérperas ou de mães com crianças com até 12 anos de idade sob sua responsabilidade, e das próprias crianças", autuado sob o n. 143.641. A Segunda Turma do STF concedeu a ordem para determinar a substituição da prisão preventiva pela domiciliar, estendendo, de ofício, às mães de pessoas com deficiência e às adolescentes em medida socioeducativa de internação. A ementa do julgado é a seguinte:

HABEAS CORPUS COLETIVO. ADMISSIBILIDADE. DOUTRINA BRASILEIRA DO HABEAS CORPUS. MÁXIMA EFETIVIDADE DO WRIT. MÃES E GESTANTES PRESAS. RELAÇÕES SOCIAIS MASSIFICADAS E BUROCRATIZADAS. GRUPOS SOCIAIS VULNERÁVEIS. ACESSO À JUSTIÇA. FACILITAÇÃO. EMPREGO DE REMÉDIOS PROCESSUAIS ADEQUADOS. LEGITIMIDADE ATIVA. APLICAÇÃO ANALÓGICA DA LEI 13.300/2016. MULHERES GRÁVIDAS OU COM CRIANÇAS SOB SUA GUARDA. PRISÕES

\footnotetext{
${ }^{43}$ BRASIL. Lei n. 13.257, de 8 de março de 2016. Dispõe sobre as políticas públicas para a primeira infância e altera a Lei $n^{\circ}$ 8.069, de 13 de julho de 1990 (Estatuto da Criança e do Adolescente), o Decreto-Lei $n^{\circ}$ 3.689, de 3 de outubro de 1941 (Código de Processo Penal), a Consolidação das Leis do Trabalho (CLT), aprovada pelo Decreto-Lei $n^{\circ} 5.452$, de $1^{\circ}$ de maio de 1943, a Lei $n^{\circ} 11.770$, de 9 de setembro de 2008 , e a Lei $n^{\circ}$ 12.662, de 5 de junho de 2012. Disponível em: http://www.planalto.gov.br/ccivil_03/_Ato20152018/2016/Lei/L13257.htm. Acesso em: 25 set. 2019.

${ }^{44}$ BRASIL. Decreto-Lei n. 3.689, de 3 de outubro de 1941. Código de Processo Penal. Disponível em: http:// www.planalto.gov.br/ccivil_03/decreto-lei/del3689compilado.htm. Acesso em: 25 set. 2019.

${ }^{45}$ BRAGA, Ana Gabriela; FRANKLIN, Naila Ingrid Chaves. Quando a casa é a prisão: uma análise de decisões de prisão domiciliar de grávidas e mães após a Lei 12.403/2011. Quaestio luris, Rio de Janeiro, v. 9, p. 349-375, 2016. http://dx.doi.org/10.12957/rqi.2016.18579. Disponível em: https://www.epublicacoes.uerj.br/index.php/quaestioiuris/article/download/18579/15789.

${ }^{46}$ Id. Ibid.
} 
PREVENTIVAS CUMPRIDAS EM CONDIÇÕES DEGRADANTES. INADMISSIBILIDADE. PRIVAÇÃO DE CUIDADOS MÉDICOS PRÉ-NATAL E PÓS-PARTO. FALTA DE BERÇARIOS E CRECHES. ADPF 347 MC/DF. SISTEMA PRISIONAL BRASILEIRO. ESTADO DE COISAS INCONSTITUCIONAL. CULTURA DO ENCARCERAMENTO. NECESSIDADE DE SUPERAÇÃO. DETENÇÕES CAUTELARES DECRETADAS DE FORMA ABUSIVA E IRRAZOÁVEL. INCAPACIDADE DO ESTADO DE ASSEGURAR DIREITOS FUNDAMENTAIS ÀS ENCARCERADAS. OBJETIVOS DE DESENVOLVIMENTO DO MILÊNIO E DE DESENVOLVIMENTO SUSTENTÁVEL DA ORGANIZAÇÃO DAS NAÇÕES UNIDAS. REGRAS DE BANGKOK. ESTATUTO DA PRIMEIRA INFÂNCIA. APLICAÇÃO À ESPÉCIE. ORDEM CONCEDIDA. EXTENSÃO DE OFÍCIO. I - Existência de relações sociais massificadas e burocratizadas, cujos problemas estão a exigir soluções a partir de remédios processuais coletivos, especialmente para coibir ou prevenir lesões a direitos de grupos vulneráveis. II - Conhecimento do writ coletivo homenageia nossa tradição jurídica de conferir a maior amplitude possível ao remédio heroico, conhecida como doutrina brasileira do habeas corpus. III - Entendimento que se amolda ao disposto no art. 654, $\$ 2^{\circ}$, do Código de Processo Penal - CPP, o qual outorga aos juízes e tribunais competência para expedir, de ofício, ordem de habeas corpus, quando no curso de processo, verificarem que alguém sofre ou está na iminência de sofrer coação ilegal. IV - Compreensão que se harmoniza também com o previsto no art. 580 do CPP, que faculta a extensão da ordem a todos que se encontram na mesma situação processual. V - Tramitação de mais de 100 milhões de processos no Poder Judiciário, a cargo de pouco mais de 16 mil juízes, a qual exige que o STF prestigie remédios processuais de natureza coletiva para emprestar a máxima eficácia ao mandamento constitucional da razoável duração do processo e ao princípio universal da efetividade da prestação jurisdicional VI - A legitimidade ativa do habeas corpus coletivo, a princípio, deve ser reservada àqueles listados no art. 12 da Lei 13.300/2016, por analogia ao que dispõe a legislação referente ao mandado de injunção coletivo. VII - Comprovação nos autos de existência de situação estrutural em que mulheres grávidas e mães de crianças (entendido o vocábulo aqui em seu sentido legal, como a pessoa de até doze anos de idade incompletos, nos termos do art. $2^{\circ}$ do Estatuto da Criança e do Adolescente - ECA) estão, de fato, cumprindo prisão preventiva em situação degradante, privadas de cuidados médicos pré-natais e pós-parto, inexistindo, outrossim berçários e creches para seus filhos. VIII - "Cultura do encarceramento" que se evidencia pela exagerada e irrazoável imposição de prisões provisórias a mulheres pobres e vulneráveis, em decorrência de excessos 
na interpretação e aplicação da lei penal, bem assim da processual penal, mesmo diante da existência de outras soluções, de caráter humanitário, abrigadas no ordenamento jurídico vigente. IX - Quadro fático especialmente inquietante que se revela pela incapacidade de o Estado brasileiro garantir cuidados mínimos relativos à maternidade, até mesmo às mulheres que não estão em situação prisional, como comprova o "caso Alyne Pimentel", julgado pelo Comitê para a Eliminação de todas as Formas de Discriminação contra a Mulher das Nações Unidas. X - Tanto o Objetivo de Desenvolvimento do Milênio nº 5 (melhorar a saúde materna) quanto o Objetivo de Desenvolvimento Sustentável $\mathrm{n}^{\circ}$ 5 (alcançar a igualdade de gênero e empoderar todas as mulheres e meninas), ambos da Organização das Nações Unidas, ao tutelarem a saúde reprodutiva das pessoas do gênero feminino, corroboram o pleito formulado na impetração. X - Incidência de amplo regramento internacional relativo a Direitos Humanos, em especial das Regras de Bangkok, segundo as quais deve ser priorizada solução judicial que facilite a utilização de alternativas penais ao encarceramento, principalmente para as hipóteses em que ainda não haja decisão condenatória transitada em julgado. XI - Cuidados com a mulher presa que se direcionam não só a ela, mas igualmente aos seus filhos, os quais sofrem injustamente as consequências da prisão, em flagrante contrariedade ao art. $227 \mathrm{da}$ Constituição, cujo teor determina que se dê prioridade absoluta à concretização dos direitos destes. XII - Quadro descrito nos autos que exige o estrito cumprimento do Estatuto da Primeira Infância, em especial da nova redação por ele conferida ao art. 318, IV e V, do Código de Processo Penal. XIII - Acolhimento do writ que se impõe de modo a superar tanto a arbitrariedade judicial quanto a sistemática exclusão de direitos de grupos hipossuficientes, típica de sistemas jurídicos que não dispõem de soluções coletivas para problemas estruturais. XIV - Ordem concedida para determinar a substituição da prisão preventiva pela domiciliar - sem prejuízo da aplicação concomitante das medidas alternativas previstas no art. 319 do CPP - de todas as mulheres presas, gestantes, puérperas ou mães de crianças e deficientes, nos termos do art. $2^{\circ}$ do ECA e da Convenção sobre Direitos das Pessoas com Deficiências (Decreto Legislativo 186/2008 e Lei 13.146/2015), relacionadas neste processo pelo DEPEN e outras autoridades estaduais, enquanto perdurar tal condição, excetuados os casos de crimes praticados por elas mediante violência ou grave ameaça, contra seus descendentes ou, ainda, em situações excepcionalíssimas, as quais deverão ser devidamente fundamentadas pelos juízes que denegarem o benefício. XV - Extensão da ordem de ofício a todas as demais mulheres presas, gestantes, puérperas ou mães de crianças e de pessoas com deficiência, bem assim às adolescentes sujeitas a medidas socioeducativas em idêntica situação no 
território nacional, observadas as restrições acima. (HC 143641, Relator(a): Min. RICARDO LEWANDOWSKI, Segunda Turma, julgado em 20/02/2018, PROCESSO ELETRÔNICO DJe-215 DIVULG 08-10-2018 PUBLIC 09-10-2018) ${ }^{47}$

O voto do ministro Ricardo Lewandowski destacou que o cuidado com a saúde materna deve ser prioridade dos países comprometidos internacionalmente com os direitos humanos e que o Estado brasileiro mostra-se incapaz de "garantir cuidados mínimos relativos à maternidade, até mesmo às mulheres que não estão em situação prisional". O ministro relator valeu-se tanto dos argumentos embasados nos direitos humanos quanto de uma lógica utilitária:

Em suma, quer sob o ponto de vista da proteção dos direitos humanos, quer sob uma ótica estritamente utilitarista, nada justifica manter a situação atual de privação a que estão sujeitas as mulheres presas e suas crianças, as quais, convém ressaltar, não perderam a cidadania, em razão da deplorável situação em que se encontram.

A decisão de substituição da prisão preventiva pela domiciliar baseia-se em diversos fatores da realidade fática e jurídica brasileira, notadamente a condenação do Brasil, pelo Comitê para a Eliminação de todas as Formas de Discriminação contra a Mulher (CEDAW, na sigla em inglês), pela morte materna de Alyne Pimentel. Dentre as recomendações desse órgão do Sistema ONU, está o dever de “assegurar o direito da mulher à maternidade saudável e o acesso de todas as mulheres a serviços adequados de emergência obstétrica" (tradução nossa) ${ }^{48}$, sendo que esse órgão determina que todas as mulheres recebam o atendimento adequado porque reconheceu que, no caso Alyne, sua condição de mulher negra e da periferia foi determinante para seu óbito. Nesse sentido, a jurisprudência do HC n. 143.641 está em consonância com o determinado pelo CEDAW, pois, se para as mulheres em geral o Brasil já é ineficiente na prevenção da mortalidade materna, muito mais o é para aquelas que sofrem uma ou múltiplas discriminações.

A maioria das mulheres encarceradas é negra e de baixa escolaridade ${ }^{49}$. A saúde materna é uma questão de direitos humanos e, no Brasil, pode-se atribuir a mortalidade materna a causas institucionais: falhas nos sistemas de saúde, violência

\footnotetext{
${ }^{47}$ SUPREMO TRIBUNAL FEDERAL - STF. Habeas Corpus 143641. Disponível em: http://portal.stf.jus.br/ processos/detalhe.asp?incidente $=5183497$. Acesso em: 25 set. 2019 .

${ }^{48}$ No original: "Ensure women's right to safe motherhood and affordable access for all women to adequate emergency obstetric care, [...]". UNITED NATIONS. Convention on the Elimination of all Forms of Discrimination against Women. CEDAW/C/49/D/17/2008. p. 21. Disponivel em: https://undocs.org/ CEDAW/C/49/D/17/2008. Acesso em: 25 set. 2019.

${ }^{49}$ MINISTÉRIO DA JUSTIÇA E DA SEGURANÇA PÚBLICA. Departamento Penitenciário Nacional. Levantamento nacional de informações penitenciárias. 2. ed. Infopen Mulheres. Brasília-DF, 2018. Disponível em: http:// depen.gov.br/DEPEN/depen/sisdepen/infopen-mulheres/infopenmulheres_arte_07-03-18.pdf.
} 
institucional e omissão estatal - o que se verificou pelo CEDAW no "Caso Alyne". A concessão do HC é uma resposta, pois demonstra reconhecimento estatal ao cuidado que deve ser prestado a mulheres gestantes e mães no exercício de uma maternidade segura, notadamente às vítimas de discriminações. Contudo, essas mulheres, se recolhidas em prisão domiciliar, devem ter disponível um atendimento obstétrico de qualidade nas unidades de saúde em que são referenciadas, ou de nada adianta a conversão do regime.

Vê-se, então, que no Brasil o desenvolvimento de uma maternidade saudável como pauta de direitos reprodutivos e de direitos humanos, bem como de saúde pública, já é uma realidade em debate, inclusive em relação ao encarceramento feminino. Reconhecendo o sistema penal como seletivo, entende-se que as mulheres que acabam recolhidas são justamente aquelas que já estão à margem - as mulheres negras e as mulheres moradoras da periferia. Assim, são justamente os mais vulneráveis e hipossuficientes que acabam por crescer longe das mães, numa reprodução das desigualdades que marca pessoas e grupos pelo resto de suas vidas. A decisão é adequada para evitar o agravamento dessa situação - mas é insuficiente se o tratamento adequado de saúde para as gestantes não aparecer também no SUS.

Ainda, sua efetiva aplicação pelos juízos da execução criminal deve ser monitorada, ao passo que a decisão, ainda que surta seus efeitos normativos, não impõem, per si, adoção automática nas comarcas. Além disso, a decisão não se aplica a todos os casos em que a apenada possui filhos, excetuadas prisões definitivas por crimes praticados mediante violência ou grave ameaça contra seus descendentes ou, ainda, em situações excepcionalíssimas, as quais deverão ser devidamente fundamentadas pelos juízes que denegarem o benefício. Ou seja, existe uma parcela de mulheres que não será atingida pela decisão, mantendo-se a situação de desamparo e desrespeito aos direitos, consoante às situações carcerárias acima expostas.

\section{Considerações finais}

O objetivo deste artigo foi comentar a jurisprudência presente no julgado do HC n. 143.641 a partir de uma visão de direitos reprodutivos. Assim, a conceituação de direitos reprodutivos para este estudo é feita a partir da inclusão no rol dos direitos humanos das mulheres. É importante compreender os direitos reprodutivos para além das liberdades individuais, como um direito social que depende da efetivação de outros direitos sociais (como o da saúde), para evitar uma visão limitada, que não observe o papel da raça e da classe social - marcadores sociais importantes neste debate, sobretudo na análise da realidade do encarceramento brasileiro.

Acerca do HC n. 143.641, impetrado em nome das mulheres gestantes ou mães, nos termos da alteração legislativa do CPP, demonstra-se uma preocupação do Estado brasileiro com a maternidade, inclusive quando exercida por mulheres marginalizadas no discurso corrente de direitos reprodutivos, indo também ao 
encontro da doutrina de proteção integral para a garantia não só dos direitos reprodutivos das mulheres, como também do desenvolvimento pleno de seus filhos, o que, como visto, não pode ser garantido no cárcere. Na jurisprudência em estudo, o STF determinou a substituição de pena preventiva pela domiciliar para todas as mulheres presas que ostentem a condição de gestantes, puérperas e mães de crianças ou de deficientes sob sua guarda, em um julgado cuja linguagem se aproxima da demanda de direitos reprodutivos pelo exercício de uma maternidade saudável e segura e vai ao encontro do que preceituam as determinações sobre o tema presentes no rol dos direitos humanos.

Naturalmente, o julgado ainda pode ser tomado de diversas outras perspectivas, como os direitos das crianças e a criminologia crítica. Este artigo objetivou propor um olhar de direitos reprodutivos, cujo enfoque está nas mulheres, mães que estão recolhidas no sistema prisional, para contribuir com o debate sobre a maternidade no cárcere em relação à realidade brasileira.

\section{Referências}

BATISTA, Nilo. Introdução crítica ao direito penal brasileiro. 11. ed. Rio de Janeiro: Revan, 2007.

BRAGA, Ana Gabriela; FRANKLIN, Naila Ingrid Chaves. Quando a casa é a prisão: uma análise de decisões de prisão domiciliar de grávidas e mães após a Lei 12.403/2011. Quaestio Iuris, Rio de Janeiro, v. 9, p. 349-375, 2016. http://dx.doi.org/10.12957/rqi.2016.18579. Disponível em: https://www.e-publicacoes.uerj.br/index.php/quaestioiuris/article/ download/18579/15789.

CAMPOS, Carmem Hein de (Org.). Criminologia e feminismo. Porto Alegre-RS: Sulina, 1999.

CARVALHO, Salo de. Criminologia cultural, complexidade e as fronteiras de pesquisa nas ciências criminais. Revista Brasileira de Ciências Criminais, São Paulo, v. 17, n. 81, p. 294-338, nov./dez. 2009.

CHRISTIE, Nils. Los Límites del dolor. México: Fondo de Cultura Económica, 1984.

CORREA, Sonia; PETCHESKY, Rosalind. Direitos sexuais e reprodutivos: uma perspectiva feminista. Physis [online]. 1996, v. 6, n. 1-2, p. 147-177. http://dx.doi.org/10.1590/S010373311996000100008. Disponível em: http://www.scielo.br/pdf/physis/v6n1-2/08.pdf.

ESPINOZA, Olga. A mulher encarcerada em face do poder punitivo. São Paulo: IBCCRIM, 2004.

ESPINOZA, Olga. A prisão feminina desde um olhar da criminologia feminista. Revista Transdisciplinar de Ciências Penitenciárias, Pelotas, v.1, n. 1, p. 35, jan./dez. 2002. Disponível em: https://antares.ucpel.tche.br/ojs/index.php/PENIT/article/viewFile/34/33. Acesso em: 18 jul. 2012.

FERRERO, Guglielmo; LOMBROSO, Cesare. La donna delinquente, la prostituta e la donna normale. Firenze: Torino, 1903. 
GARCÍA, Carmen Antony. Mujeres invisibles: las cárceres femeninas en América Latina. Nueva Sociedad, n. 208, p. 73-85, mar./abr. 2007. Disponível em: https://nuso.org/articulo/ las-carceles-femeninas-en-america-latina/. Acesso em: 11 jul. 2019.

GOFFMAN, Erving. Manicômios, prisões e conventos. São Paulo: Perspectiva, 1974.

HULSMAN, Louk; CELIS, Jacqueline Bernat de. Penas perdidas: o sistema penal em questão. Rio de Janeiro: Luam, 1993.

LARRAURI, Elena. A mujer ante el derecho penal. Revista de la Asociación de Ciencias Penales de Costa Rica, año 9, n. 11, p. 13-45, jul. 1996.

LEMGRUBER, Julita. Cemitério dos vivos: análise sociológica de uma prisão de mulheres. Rio de Janeiro: Forense, 1999.

MARRONE ALIMENA, Carla. A tentativa do (im)possível: feminismos e criminologias. Rio de Janeiro: Lumen Juris, 2010.

MINISTÉRIO DA JUSTIÇA E DA SEGURANÇA PÚBLICA. Departamento Penitenciário Nacional. Levantamento nacional de informações penitenciárias. 2. ed. Infopen Mulheres. Brasília-DF, 2018. Disponível em: http://depen.gov.br/DEPEN/depen/sisdepen/infopenmulheres/infopenmulheres_arte_07-03-18.pdf.

OLIVEIRA, Odete Maria de. A mulher e o fenômeno da criminalidade. In ANDRADE, Vera Regina Pereira de (Org.). Verso e reverso do controle penal (des) aprisionando a sociedade da cultura punitiva. Florianópolis-SC: Fundação Boiuteux, 2003. v. 1.

PETCHESKY, R. Spiraling discourses of reproductive and sexual rights: A Post-Beijing assessment of international feminist politics. In: COHEN, C; JONES, K; TRONTO, 5. Women transforming politics: An alternative reader. Nova York : NYU Press, 1997, pp. 569-587.

RODRIGUES, Carla. Butler e a desconstrução do gênero [Resenha]. Rev. Estud. Fem., Florianópolis, v. 13, n. 1, p. 179-183, jan./abr. 2005. http://dx.doi.org/10.1590/S0104026X2005000100012. Disponível em: http://www.scielo.br/pdf/ref/v13n1/a12v13n1.pdf. Acesso em: 11 jul. 2019.

SARLET, Ingo Wolfgang. A eficácia dos direitos fundamentais. 9. ed., rev., atual. e ampl. Porto Alegre: Livr. do Advogado, 2008.

SOARES, Barbára; SILVA, Iara Ilgenfritz. Prisioneiras: vida e violência atrás das grades. Rio de Janeiro: Garamond, 2002.

SUPERINTENDÊNCIA DOS SERVIÇOS PENITENCIÁRIOS - SUSEPE. Departamento de Planejamento. Relatório atualizado em 10/07/2019. Disponível em: http://www.susepe.rs.gov. br/capa.php. Acesso em 19 jul. 2019.

TRINDADE, Jorge. Manual de psicologia jurídica para operadores do direito. Porto Alegre: Liv. do Advogado, 2004. 
UNITED NATIONS POPULATION FUND - UNFPA. Report of the International Conference on Population and Development. Cairo, 5-13 Sept. 1994. New York: United Nations, 1995. Disponível em: https://www.un.org/en/development/desa/population/events/pdf/expert/27/ SupportingDocuments/A_CONF.171_13_Rev.1.pdf.

UNITED NATIONS - NS. Convention on the Elimination of all Forms of Discrimination against Women. CEDAW/C/49/D/17/2008. Disponível em: https://undocs.org/CEDAW/ C/49/D/17/2008. Acesso em: 25 set. 2019.

UNITED NATIONS - NS. Fourth World Conference on Women. Beijing Declaration and Plataform for Action. Pequim, 1995. Disponível em: https://www.un.org/en/events/pastevents/ pdfs/Beijing_Declaration_and_Platform_for_Action.pdf.

VENTURA, Miriam. Direitos reprodutivos no Brasil. Brasília-DF: UNFPA, 2009.

ZIMERMAN, David; COLTRO, Antônio Carlos Mathias. (Orgs.). Aspectos psicológicos da atividade jurídica. Campinas: Millennium, 2002.

Marina Nogueira de Almeida - Mestrado em Direito, com ênfase em direitos humanos, pelo Centro Universitário Ritter dos Reis; especialização em Direito Processual Civil pela Faculdade Estácio. Advogada. Porto Alegre/RS, Brasil.E-mail: almeida.marinan@gmail.com

Larissa Urruth Pereira - Doutoranda em Ciências Sociais pela Pontifícia Universidade Católica do Rio Grande do Sul (PUC-RS); mestrado em Ciências Criminais pela PUC-RS; especialização em Ciências Penais pela PUC-RS. Professora das disciplinas de Teoria da Pena e de Leis Penais Especiais no Centro Universitário Cenecista de Osório. Advogada. Porto Alegre/RS, Brasil. 